\title{
Price competition model in decentralized and centralized supply chains with demand disruption
}

\author{
Chai Wenlong ${ }^{1}$, Sun Huijun ${ }^{1}$, Wei Wang ${ }^{1}$, Jianjun $\mathrm{Wu}^{2}$ \\ ${ }^{1}$ Moe Key Laboratory for Urban Transportation Complex Systems Theory, ${ }^{2}$ State Key Laboratory of Rail Traffic \\ Control and Safety, Beijing Jiaotong University (China) \\ chaiwenl@,gmail.com; hjsun@,bjtu.edu.cn;.nwang@,bjtu.edu.cn;jïwn@bjtu.edu.cn
}

Received November 2012

Accepted February 2013

\section{Abstract:}

Purpose: The paper studies the price competition of a supply chain with one supplier and two competing retailers under occasional demand disruption.

Design/methodology/approach: The supply chain is either decentralized or centralized. The demand disruption for two retailers occurs with different probability. We analyze the effect of occurrence probability of demand distuption on the optimal prices of the supplier and two retailers.

Findings: We find that the profits of supplier, retailers and supply chain are decreasing with the occurrence probability of demand disruption.

Originality/value: It is helpful for supply chain members to adjust the original contracts to demand disruption.

Keywords: Demand disruption; Probability; Price competition; Profit 


\section{Introduction}

The market demand is often disrupted by some haphazard events, such as the promotion of sale, the raw material shortage, the new tax or tariff policy, machine breakdown, and so on. All the retailers and suppliers in the entire supply chain will be severely affected by these demand disruptions (Qi, Bard \& Yu, 2004; Huang, Yu, Wang \& Wang, 2006; Xiao \& Yu, 2006). Therefore, the issue of supply chain management under demand disruptions has been an active research topic in recent years.

This paper focus on the supply chain under demand disruptions when retailers compete. Xiao, Yu, Sheng \& Xia (2005) studied the coordination of a supply chain system with one manufacturer and two competing retailers when there are demand disruptions. A price-subsidy rate contract is considered to coordinate the investments of the competing retailers with sales promotion opportunities and demand disruptions. Xiao, Qi and Yu (2007) studied the coordination of the supply chain with demand disruptions in the cases of a linear quantity discount schedule or an all-unit quantity discount schedule. Xiao and Qi (2008) investigated how to coordinate a supply chain with one manufacturer and two competing retailers using an all-unit quantity discount or an incremental quantity discount after the production cost of the manufacturer was disrupted. Chen and Xiao (2009) considered two coordination schedules, a linear quantity discount schedule and a Groves wholesale price schedule, to coordinate a supply chain consisting of one manufacturer, one dominant retailer and multiple fringe retailers after demand disruptions. Zhang, Fu, Li and Xu (2012) investigated how to coordinate a supply chain with one manufacturer and two retailers under demand disruptions by revenue-sharing contracts.

The above papers mainly focused on the competition and coordination of a supply chain after demand disruptions. These researches all assumed that the demand disruption of a supply chain would occur in the future. However, the occurrence of demand disruption cannot be determined (Xu, Qi, Yu, Zhang \& Gao, 2003; Yu \& Qi, 2004; Yang, Qi, \& Yu, 2005).

In this paper, we will consider the demand disruption of a supply chain with a single supplier and two retailers who compete in the market. Our particular interest is the occurrence probability of demand disruption on each retailer. We explore the effects of demand disruption uncertainty on the supply chain.

The rest of the paper is organized as follows. Section 2 introduces the basic model when demand disruption occurs. Section 3 studies the demand disruptions in decentralized and centralized supply chains. Some numerical examples are given in Section 4 to elaborate our results. Finally, Section 5 provides conclusions. 


\section{Basic model}

We consider a supply chain consisting of one supplier and two competing retailers. It is either integrated where the manufacturer 'owns' her two exclusive retailers or decentralized where the manufacturer sells its product to the market through retailers. The supplier is a leader and the retailers are followers. We have the following notations $(i=1,2)$ :

$w_{o}$ : the unit wholesale price of supplier;

$\alpha_{\mathrm{i}}: \quad$ the market scale for retailer $i$;

$d_{i}:$ the degree of substitutability between retailers, $0<d_{i}<1$;

$p_{i}:$ the retail price of retailer $i$

$q_{i}:$ the market demand for retailer $i$

$\varphi_{i}:$ the probability of demand disruption on retailer $i$;

$\pi_{i}:$ the profit of retailer $i$

$\pi_{0}:$ the profit of supplier;

$\Pi$ : the total profit of the supply chain;

We assume that the demand function of retailer $i$ is:

$$
q_{i}\left(p_{i}, p_{j}\right)=\alpha_{i}-p_{i}+d_{i} p_{j}, \quad i, j=1,2, \quad i \neq j
$$

The substitutability coefficient $d_{i}$ is a measure of the sensitivity of the ith retailer's sales to the change of jth retailer's price. When the demand disruption occurs, the market scale or the demand for retailer $i$ will change. Then the demand function of retailer $i$ is:

$$
q_{i}^{\prime}\left(p_{i}, p_{j}\right)=\alpha_{i}^{\prime}-p_{i}+d_{i}^{\prime} p_{j}
$$

where $\alpha_{i}{ }^{\prime}$ is the market scale for retailer $i$ after demand disruption, $d_{i}{ }^{\prime}$ is the substitutability coefficient under demand disruption.

We assume that the new market scale $\alpha_{i}{ }^{\prime}$ for retailer $i$ is:

$$
\alpha_{i}^{\prime}=\alpha_{i}+\Delta \alpha_{i}
$$


with a positive $\Delta \alpha_{i}$ representing an increased market demand, and a negative $\Delta \alpha_{i}$ representing a decreased market demand. Similarly, the new substitutability coefficient is:

$$
d_{i}^{\prime}=d_{i}+\Delta d_{i}
$$

\section{Demand disruptions in decentralized and centralized supply chains}

\subsection{Demand disruptions in a decentralized and centralized supply chain}

We consider a supply chain consisting of one supplier and two competing retailers. For a decentralized supply chain (DSC), the supplier produces goods with a unit production cost and sells the product through the retailers. After purchasing the product from the supplier with a unit wholesale price, retailers add some values to the product with a unit selling cost, and then determine his retail price to sell the product. For simplicity, we assume that the costs above are normalized to zero.

Thus, the profit of the supplier is:

$$
\pi_{0}=\sum_{i=1, j \neq i}^{2} w_{0}\left(\alpha_{i}^{\prime}-p_{i}+d_{i}^{\prime} p_{j}\right) \varphi_{i}+w_{0}\left(\alpha_{i}-p_{i}+d_{i} p_{j}\right)\left(1-\varphi_{i}\right)
$$

Substituting Eqs. (3) and (4) into Eq. (5), we have:

$$
\pi_{0}=\sum_{i=1, j \neq i}^{2} w_{0}\left[\alpha_{i}+\Delta \alpha_{i} \varphi_{i}+\left(d_{j}+\Delta d_{j} \varphi_{j}-1\right) p_{i}\right]
$$

We can also obtain the profit of the retailer $i$.

$$
\pi_{i}=\left(p_{i}-w_{0}\right)\left[\alpha_{i}+\Delta \alpha_{i} \varphi_{i}-p_{i}+\left(d_{i}+\Delta d_{i} \varphi_{i}\right) p_{j}\right]
$$

Differentiating Eqs. (7), we have the optimal retail price of retailers for any given wholesale price.

$$
p_{i}=\frac{\left(d_{i}+\Delta d_{i} \varphi_{i}+2\right) w_{0}+2\left(\alpha_{i}+\Delta \alpha_{i} \varphi_{i}\right)+\left(\alpha_{j}+\Delta \alpha_{j} \varphi_{j}\right)\left(d_{i}+\Delta d_{i} \varphi_{i}\right)}{4-\left(d_{i}+\Delta d_{i} \varphi_{i}\right)\left(d_{j}+\Delta d_{j} \varphi_{j}\right)}
$$

Inserting Eq. (8) into Eq. (6) and for the first order conditions, we have the optimal wholesale price of supplier.

$$
w_{0}^{*}=\frac{A_{i}\left(D_{j}+2\right)+A_{j}\left(D_{i}+2\right)}{2\left(4-D_{i}-D_{j}-2 D_{i} D_{j}\right)}
$$


where $A_{i}=\alpha_{i}+\Delta \alpha_{i} \varphi_{i}, A_{j}=\alpha_{j}+\Delta \alpha_{j} \varphi_{j}, D_{i}=d_{i}+\Delta d_{i} \varphi_{i}, D_{j}=\alpha_{j}+\Delta \alpha_{j} \varphi_{j}$.

With the optimal wholesale price, we can obtain the optimal retail price of retailer $i$.

$$
p_{i}^{*}=\frac{\left(D_{i}+2\right)\left[A_{i}\left(D_{j}+2\right)+A_{j}\left(D_{i}+2\right)\right]+2\left(4-D_{i}-D_{j}-2 D_{i} D_{j}\right)\left(2 A_{i}+A_{j} D_{i}\right)}{2\left(4-D_{i}-D_{j}-2 D_{i} D_{j}\right)\left(4-D_{i} D_{j}\right)}
$$

By substituting Eqs. (9) and (10) into (6) and (7), we can obtain the profit of each supply chain member.

\subsection{Demand disruption in a centralized supply chain}

For a centralized supply chain (CSC), the supplier 'owns' the two exclusive retailers. Her problem is to determine the retail price of each retailer so as to maximize the total profit of the centralized supply chain.

The total profit of the centralized supply chain can be defined as:

$$
\Pi=\sum_{i=1, j \neq i}^{2} p_{i}\left(\alpha_{i}^{\prime}-p_{i}+d_{i}^{\prime} p_{j}\right) \varphi_{i}+p_{i}\left(\alpha_{i}-p_{i}+d_{i} p_{j}\right)\left(1-\varphi_{i}\right)
$$

Substituting Eqs. (3) and (4) into Eq. (11), we have:

$$
\Pi=\sum_{i=1, j \neq i}^{2} p_{i}\left[\alpha_{i}+\Delta \alpha_{i} \varphi_{i}+\left(d_{j}+\Delta d_{j} \varphi_{j}-1\right) p_{i}\right]
$$

Differentiating Eq.(12) and solving for equilibrium retail price for both retailers simultaneously, we obtain:

$$
p_{i}^{*}=-\frac{2 A_{i}+A_{j}\left(D_{i}+D_{j}\right)}{\left(D_{i}+D_{j}+2\right)\left(D_{i}+D_{j}-2\right)}
$$

With the optimal retail prices, we can obtain the profit of the centralized supply chain.

\section{Numerical examples}

To explore the effects of the demand disruption uncertainty of the decentralized and centralized supply chains, we give some numerical examples in this section. Consider the following example with parameters: $a_{1}=a_{2}=20, d_{1}=0.5, d_{2}=0.4, \Delta a_{1}=\Delta a_{2}=-3, \Delta d_{1}=\Delta d_{2}=0.05$.

Fig. 1 and Fig. 2 illustrate how the optimal wholesale price of the supplier in decentralized supply 
chain and the optimal retail price of two retailers in decentralized or centralized supply chain depend on the occurrence probability of demand disruption. In Fig. 1, we assume that $\varphi_{1}$ is changing from 0 to 1 , and $\varphi_{2}=0.1$. In Fig. 2 , we assume that $\varphi_{2}$ is changing from 0 to 1 , and $\varphi_{1}=0.1$.

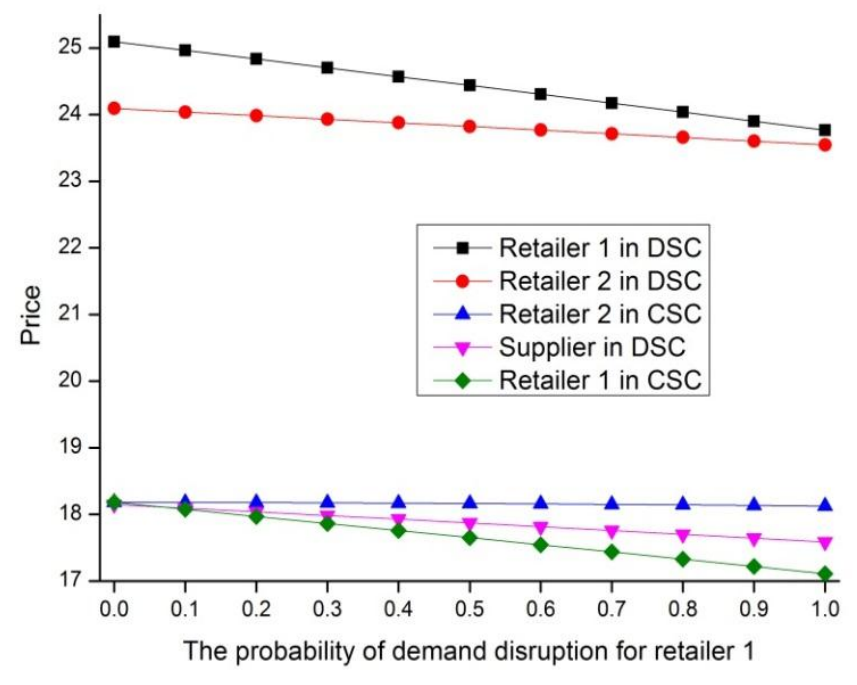

Figure 1 . The optimal wholesale and retail price versus the probability of demand disruption for retailer 1

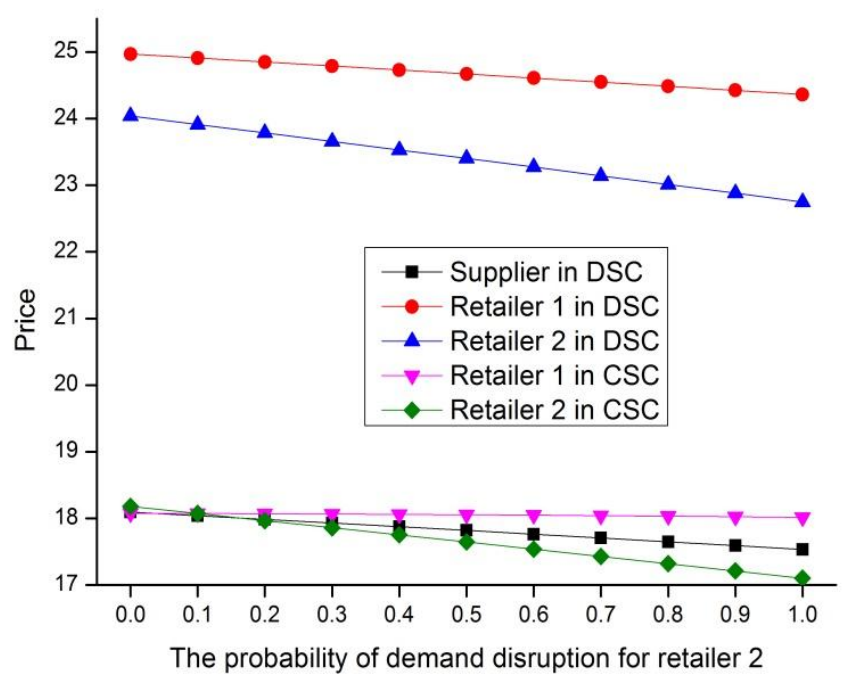

Figure 2. The optimal wholesale and retail price versus the probability of demand disruption for retailer 2

From Fig. 1 and Fig. 2, we can see that the optimal wholesale price of supplier in decentralized supply chain and the optimal retail price of two retailers in centralized or decentralized supply chain are decreasing with the with the occurrence probability of demand disruption for retailer $2 /$ retailer 1 . Because the demand for retailer $1 /$ retailer 2 drops, he would like to lower the retail 
price to sell more goods. For market competition, retailer $2 /$ retailer 1 will also bring the retail price down. And the supplier will lower his wholesale prices and share the demand disruption.

Fig. 3 and Fig. 4 illustrate how the profits of supplier, retailers and supply chain depend on the occurrence probability of demand disruption. In Fig. 3, we assume that $\varphi_{1}$ is changing from 0 to 1 , and $\varphi_{2}=0.1$. In Fig. 4 , we assume that $\varphi_{2}$ is changing from 0 to 1 , and $\varphi_{2}=0.1$.

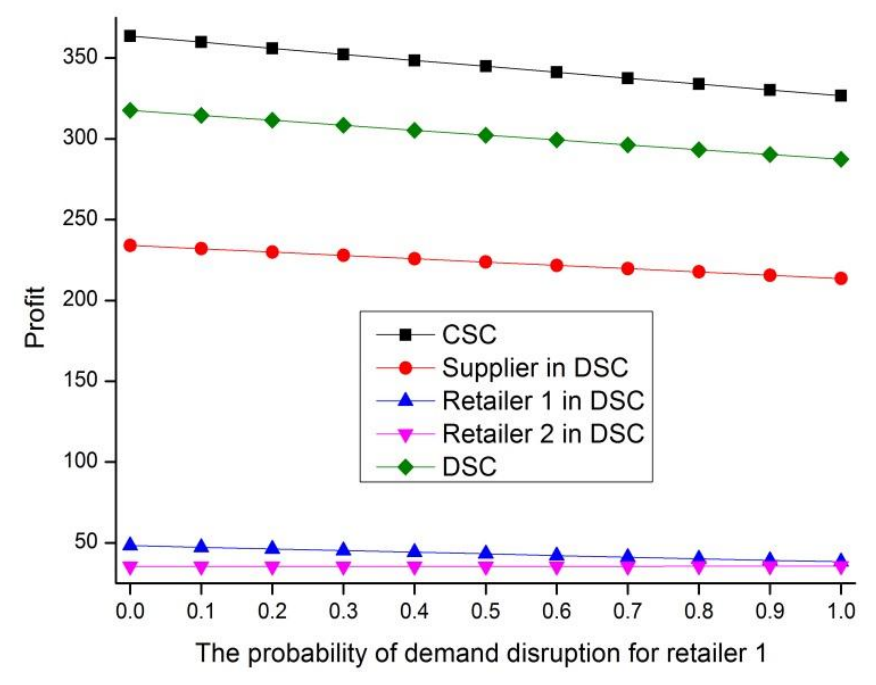

Figure 3 . The profit versus the probability of demand disruption for retailer 1

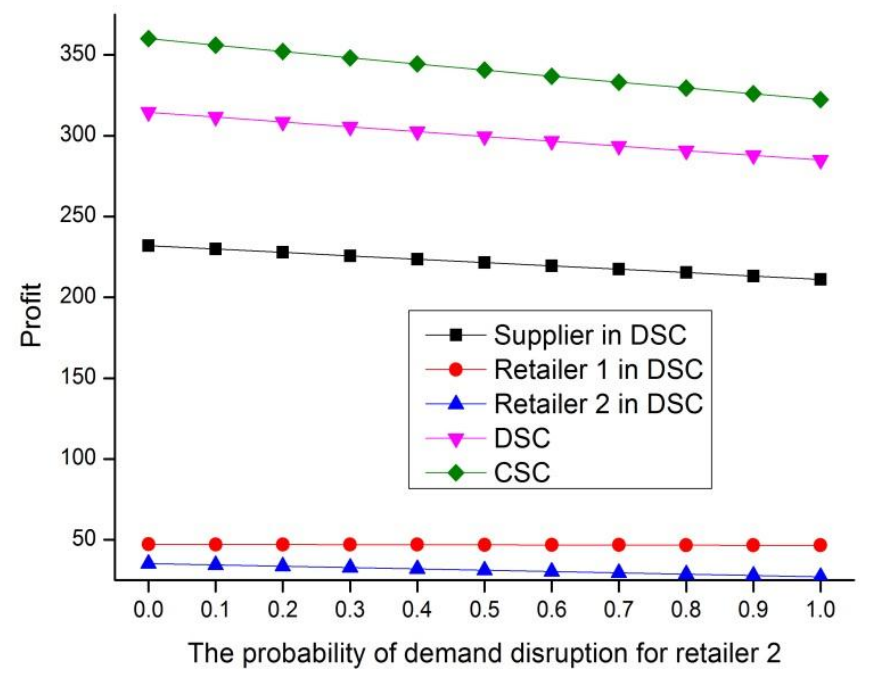

Figure 4. The profit versus the probability of demand disruption for retailer 1

From Fig. 3 and Fig. 4, we can see that the profit of CSC, members in DSC and DSC are all decreasing with the probability of demand disruption. The demand disruption reduces the profits of supply chain partners. The profit of centralized supply chain is always larger than the one of 
decentralized supply chain under the demand disruption.

\section{Conclusion}

In this paper, we study the price competition of a supply chain with one supplier and two competing retailers under occasional demand disruption. We mainly focus on the price competition of the two retailers when the demands for them are disrupted with different probability. The optimal retail prices for the two retailers in the centralized and decentralized supply chains are obtained. We found that the profits of supplier, retailers and supply chain are decreasing with the occurrence probability of demand disruption.

The demand disruption management in the supply chain is a meaningful and interesting field. In our future study, we will consider how to coordinate the supply chain by contract when demand disruptions occur.

\section{Acknowledgements}

This work is partly supported by the Beijing Natural Science Foundation (8102029), Beijing Science and Technology Star Plan (2009A15), the Fundamental Research Funds for the Central Universities (2012JBZ005) and FANEDD (201170).

\section{References}

Chen, K., \& Xiao, T. (2009). Demand disruption and coordination of the supply chain with a dominant retailer. European Journal of Operational Research, 197, 225-234. http://dx.doi.org/10.1016/j.ejor.2008.06.006

Huang, C., Yu, G., Wang, S., \& Wang, X. (2006). Disruption management for supply chain coordination with exponential demand function. Acta Mathematica Scientia, 26, 655-669. http://dx.doi.org/10.1016/S0252-9602(06)60092-1

Qi, X., Bard, J.F., \& Yu, G. (2004). Supply chain coordination with demand disruptions. International Journal of Management Science, 32, 301-312.

Xiao, T., \& Qi, X. (2008). Price competition, cost and demand disruptions and coordination of a supply chain with one manufacturer and two competing retailers. International Journal of Management Science, 36, 741-753.

Xiao, T., \& Yu, G. (2006). Supply chain disruption management and the evolution of retailers' behaviors in the quantity-setting duopoly situation with homogeneous goods. European Journal of Operational Research, 173, 648-668. http://dx.doi.org/10.1016/j.ejor.2005.02.076 
Xiao, T., Qi, X., \& Yu, G. (2007). Coordination of supply chain after demand disruptions when retailers compete. International Journal of Production Economics, 109, 162-179. http://dx.doi.org/10.1016/j.ijpe.2006.11.013

Xiao, T., Yu, G., Sheng, Z., \& Xia, Y. (2005). Coordination of a supply chain with one-manufacturer and two-retailers under demand promotion and disruption management decisions. Annals of Operations Research, 135, 87-109. http://dx.doi.org/10.1007/s10479-005-6236-6

Xu, M., Qi, X., Yu, G., Zhang, H., \& Gao, C. (2003). The demand disruption management problem for a supply chain system with nonlinear demand functions. Journal of System Science and Systems Engineering, 12, 82-97. http://dx.doi.org/10.1007/s11518-006-0122-x

Yang, J., Qi, X., \& Yu, G. (2005). Disruption management in production planning. Naval Research Logistics, 52, 420-442. http://dx.doi.org/10.1002/nav.20087

Yu, G., \& Qi, X. (2004). Disruption Management: Framework, Models and Applications. World Scientific Publisher, Singapore.

Zhang, W.G., Fu, J., Li, H., \& Xu, W. (2012). Coordination of supply chain with a revenue-sharing contract under demand disruptions when retailers compete. International Journal of Production Economics, 138, 68-75. http://dx.doi.org/10.1016/j.ijpe.2012.03.001

Journal of Industrial Engineering and Management, 2013 (www.jiem.org)

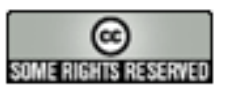

El artículo está con Reconocimiento-NoComercial 3.0 de Creative Commons. Puede copiarlo, distribuirlo y comunicarlo públicamente siempre que cite a su autor y a Intangible Capital. No lo utilice para fines comerciales. La licencia completa se puede consultar en http://creativecommons.org/licenses/by-nc/3.0/es/ 